University of Wollongong

Research Online

Faculty of Engineering and Information

Faculty of Engineering and Information

Sciences - Papers: Part A

Sciences

$1-1-2015$

\title{
An in-situ neutron diffraction study of a multi-phase transformation and twinning-induced plasticity steel during cyclic loading
}

Ahmed A. Saleh

University of Wollongong, asaleh@uow.edu.au

Donald W. Brown

Los Alamos National Laboratory

Elena V. Pereloma

University of Wollongong, elenap@uow.edu.au

Bjorn Clausen

Los Alamos National Laboratory

Christopher H. J Davies

Monash University

See next page for additional authors

Follow this and additional works at: https://ro.uow.edu.au/eispapers

Part of the Engineering Commons, and the Science and Technology Studies Commons

Research Online is the open access institutional repository for the University of Wollongong. For further information contact the UOW Library: research-pubs@uow.edu.au 


\title{
An in-situ neutron diffraction study of a multi-phase transformation and twinning- induced plasticity steel during cyclic loading
}

\author{
Abstract \\ In-situ neutron diffraction during cyclic tension-compression loading (b3.5\% to $2.8 \%$ ) of a \\ $17 \mathrm{Mn}-3 \mathrm{Al}-2 \mathrm{Si}-1 \mathrm{Ni}-0.06 \mathrm{C}$ steel that exhibits concurrent transformation and twinning -induced plasticity \\ effects indicated a significant contribution of intragranular back stresses to the observed Bauschinger \\ effect. Rietveld analysis revealed a higher rate of martensitic transformation during tension compared to \\ compression. Throughout cycling, a0-martensite exhibited the highest phase strains such that it bears an \\ increasing portion of the macroscopic load as its weight fraction evolves. On the other hand, the e- \\ martensite strain remained compressive as it accommodated most of the internal strains caused by the \\ shape misfit associated with the c!e and/or e!a0 transformations.
}

\section{Keywords}

study, multi, phase, transformation, twinning, induced, plasticity, steel, during, cyclic, loading, neutron, situ, diffraction

Disciplines

Engineering | Science and Technology Studies

\section{Publication Details}

Saleh, A. A., Brown, D. W., Pereloma, E. V., Clausen, B., Davies, C. H. J., Tome, C. N. \& Gazder, A. A. (2015). An in-situ neutron diffraction study of a multi-phase transformation and twinning-induced plasticity steel during cyclic loading. Applied Physics Letters, 106 (17), 171911-1-171911-6.

\section{Authors}

Ahmed A. Saleh, Donald W. Brown, Elena V. Pereloma, Bjorn Clausen, Christopher H. J Davies, Carlos N. Tome, and Azdiar A. Gazder 


\section{A|P Applied Physics

\section{An in-situ neutron diffraction study of a multi-phase transformation and twinning- induced plasticity steel during cyclic loading}

Ahmed A. Saleh, Donald W. Brown, Elena V. Pereloma, Bjørn Clausen, Christopher H. J. Davies, Carlos N.

Tomé, and Azdiar A. Gazder

Citation: Applied Physics Letters 106, 171911 (2015); doi: 10.1063/1.4919455

View online: http://dx.doi.org/10.1063/1.4919455

View Table of Contents: http://scitation.aip.org/content/aip/journal/apl/106/17?ver=pdfcov

Published by the AIP Publishing

\section{Articles you may be interested in}

In-situ neutron diffraction study of martensitic variant redistribution in polycrystalline Ni-Mn-Ga alloy under cyclic thermo-mechanical treatment

Appl. Phys. Lett. 105, 021907 (2014); 10.1063/1.4890598

In-situ neutron diffraction study of deformation behavior of a multi-component high-entropy alloy

Appl. Phys. Lett. 104, 051910 (2014); 10.1063/1.4863748

Anomalous plastic deformation and martensitic transformation in metastable austenitic steels at low strain rate characterized by in-situ hydrogen and argon releases and scanning probe microscopy

J. Appl. Phys. 110, 033540 (2011); 10.1063/1.3622516

Transformation-induced plasticity in an ultrafine-grained steel: An in situ neutron diffraction study

Appl. Phys. Lett. 90, 101911 (2007); 10.1063/1.2711758

In situ neutron diffraction study of grain-orientation-dependent phase transformation in $304 \mathrm{~L}$ stainless steel at a cryogenic temperature

J. Appl. Phys. 100, 123515 (2006); 10.1063/1.2402474

You don't

still use this

cell phone

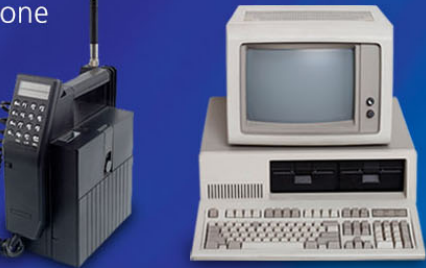

Why are you still using an AFM designed in the 80 's?
It is time to upgrade your AFM

Minimum $\$ 20,000$ trade-in discount for purchases before August 31st

Asylum Research is today's technology leader in AFM 


\title{
An in-situ neutron diffraction study of a multi-phase transformation and twinning-induced plasticity steel during cyclic loading
}

\author{
Ahmed A. Saleh, ${ }^{1, a)}$ Donald W. Brown, ${ }^{2}$ Elena V. Pereloma, ${ }^{1,3}$ Bjørn Clausen, ${ }^{2}$ \\ Christopher H. J. Davies, ${ }^{4}$ Carlos N. Tomé, ${ }^{2}$ and Azdiar A. Gazder ${ }^{3}$ \\ ${ }^{1}$ School of Mechanical, Materials and Mechatronic Engineering, University of Wollongong, Wollongong, \\ New South Wales 2522, Australia \\ ${ }^{2}$ Los Alamos National Laboratory, Los Alamos, New Mexico 87545, USA \\ ${ }^{3}$ Electron Microscopy Centre, University of Wollongong, Wollongong, New South Wales 2500, Australia \\ ${ }^{4}$ Department of Mechanical and Aerospace Engineering, Monash University, Clayton, Victoria 3800, \\ Australia
}

(Received 24 January 2015; accepted 20 April 2015; published online 30 April 2015)

\begin{abstract}
In-situ neutron diffraction during cyclic tension-compression loading $(\sim+3.5 \%$ to $-2.8 \%)$ of a $17 \mathrm{Mn}-3 \mathrm{Al}-2 \mathrm{Si}-1 \mathrm{Ni}-0.06 \mathrm{C}$ steel that exhibits concurrent transformation and twinning -induced plasticity effects indicated a significant contribution of intragranular back stresses to the observed Bauschinger effect. Rietveld analysis revealed a higher rate of martensitic transformation during tension compared to compression. Throughout cycling, $\alpha^{\prime}$-martensite exhibited the highest phase strains such that it bears an increasing portion of the macroscopic load as its weight fraction evolves. On the other hand, the $\varepsilon$-martensite strain remained compressive as it accommodated most of the internal strains caused by the shape misfit associated with the $\gamma \rightarrow \varepsilon$ and/or $\varepsilon \rightarrow \alpha^{\prime}$ transformations. (C) 2015 AIP Publishing LLC. [http://dx.doi.org/10.1063/1.4919455]
\end{abstract}

Low stacking fault energy (SFE), high-Mn (15-30 wt. \%) Transformation Induced Plasticity (TRIP) and Twinning Induced Plasticity (TWIP) steels are the current subject of intense world-wide research due to their unique combination of high strength and ductility with superior energy absorption properties. TRIP steels $\left(\mathrm{SFE}<12 \mathrm{~mJ} / \mathrm{m}^{2}\right)$ contain a metastable $\gamma$-austenite (face centered cubic) which transforms to $\varepsilon$ martensite (hexagonal close packed) and/or $\alpha^{\prime}$-martensite (approximated as body centered cubic when tetragonality is minor $(\mathrm{c} / \mathrm{a} \sim 1)$ and cannot be resolved in the diffraction patterns) during room temperature deformation. TWIP steels $\left(\mathrm{SFE} \sim 18-40 \mathrm{~mJ} / \mathrm{m}^{2}\right)$ comprise a stable $\gamma$ phase that exhibits twinning along with slip upon straining. Alternatively, TRIPTWIP steels $\left(\mathrm{SFE}=12-18 \mathrm{~mJ} / \mathrm{m}^{2}\right)$ undergo concurrent martensitic transformation, twinning, and slip. ${ }^{1}$ To this end, the present study tracks the deformation and phase transformation behavior of a TRIP-TWIP steel via in-situ neutron diffraction (ND) during cyclic (tension-compression) loading.

An as-cast $17 \mathrm{Mn}-3 \mathrm{Al}-2 \mathrm{Si}-1 \mathrm{Ni}-0.06 \mathrm{C}$ wt. $\%$ TRIP-TWIP steel was $52 \%$ hot rolled and $42 \%$ cold rolled during which most of the $\gamma$ was transformed to $\varepsilon$ and $\alpha^{\prime}$. A round (Ø2.54 mm) tension-compression sample was machined from the cold-rolled strip with its gage length $(7.62 \mathrm{~mm})$ parallel to the rolling direction. Thereafter, the sample was annealed at $900{ }^{\circ} \mathrm{C}$ for $300 \mathrm{~s}$ followed by immediate water quenching; resulting in a predominantly $\gamma$ microstructure with a small fraction $(\sim 8 \%)$ of thermally-induced $\varepsilon$.

In-situ cyclic $(\sim+3.5 \%$ to $-2.8 \%)$ ND measurements were performed on the SMARTS diffractometer at LANSCE. $^{2}$ The sample was oriented at $45^{\circ}$ to the incident beam with two detector banks parallel $\mathrm{Q}_{\|}\left(-90^{\circ}\right)$ and

\footnotetext{
${ }^{\text {a) }}$ Author to whom correspondence should be addressed. Electronic mail: asaleh@uow.edu.au. Telephone: +612-4221-3034. Fax: +612-4221-3662
}

perpendicular $\mathrm{Q}_{\perp}\left(+90^{\circ}\right)$ to the applied load. Three complete tension-compression cycles were performed followed by a fourth tension half-cycle (Fig. 1). For the first three cycles, diffraction patterns were acquired at predetermined strains followed by measurements at the maximum tension and zero unload points for the fourth half-cycle.

Rietveld refinement of complete axial diffraction patterns (Figs. 2(a) and 2(b)) was performed using GSAS $^{3}$ to track the weight fraction, inverse pole figures (IPFs), and lattice parameters of each phase. Note that: (i) differences in the weight fraction estimates from $\mathrm{Q}_{\|}$and $\mathrm{Q}_{\perp}$ are within the calculation uncertainty, and (ii) since the IPFs were constructed from single diffraction patterns with a limited number of reflections, they are only semi-quantitative representations of texture evolution. ${ }^{4}$ Here, the texture of the cubic and hexagonal phases was fitted using eighth $\left(\gamma\right.$ and $\left.\alpha^{\prime}\right)$ and sixth $(\varepsilon)$ order spherical harmonics with an axisymmetric assumption. The elastic phase strain $\left(\varepsilon_{P h}=\left(a-a^{0}\right) / a^{0}\right)$ was calculated using the instantaneous $(a)$ and unstrained $\left(a^{0}\right)$ lattice parameters. When there is no strengthening of $\varepsilon$ orientations along the $\langle 10 \overline{1} 0\rangle-\langle 11 \overline{2} 0\rangle$ line (see Figs. 4(d) and 4(e)), the average $\varepsilon$ phase strain is calculated as $\varepsilon_{\varepsilon}=\left(2 \varepsilon_{a}+\varepsilon_{c}\right) / 3$; where $\varepsilon_{a}$ and $\varepsilon_{c}$ are the lattice strains of the $a$ and $c$ lattice parameters, respectively. ${ }^{5}$ Since $\alpha^{\prime}$ did not exist initially, its $a^{0}$ was estimated following Ref. 6 such that the lattice parameter ratio between $\gamma$ and $\alpha^{\prime}$ was correlated to their densities via $a_{\alpha^{\prime}}^{0} / a_{\gamma}^{0}=\sqrt[3]{\rho_{\gamma} / \rho_{\alpha^{\prime}}}$. Here, the density of $\gamma\left(\rho_{\gamma}\right)$ and $\alpha^{\prime}\left(\rho_{\alpha^{\prime}}\right)$ was empirically calculated as proposed in Ref. 7 for multi-phase steels

$$
\begin{aligned}
\rho_{\gamma}= & 8099.79-0.5060 T-6.01 X_{\gamma}^{M n}-68.24 X_{\gamma}^{S i} \\
& +\left(1.54+2.267 \times 10^{-3} T-11.26 \times 10^{-7} T^{2}\right. \\
& \left.+0.062642 X_{\gamma}^{N i}\right) X_{\gamma}^{N i}+(-118.26+0.00739 T) X_{\gamma}^{C},
\end{aligned}
$$




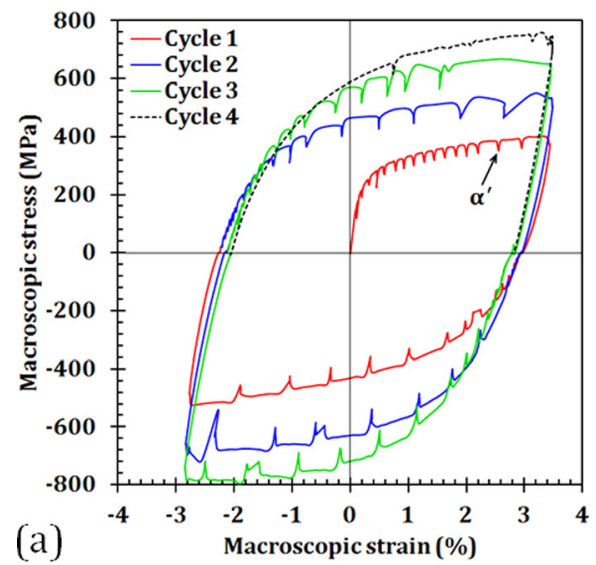

(a)

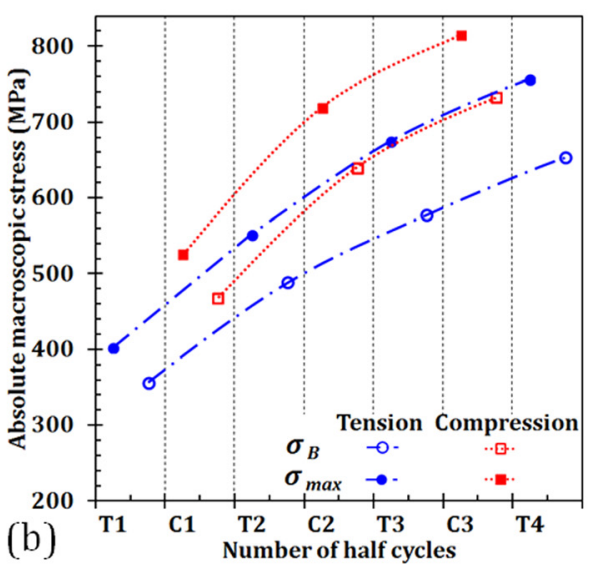

(b)

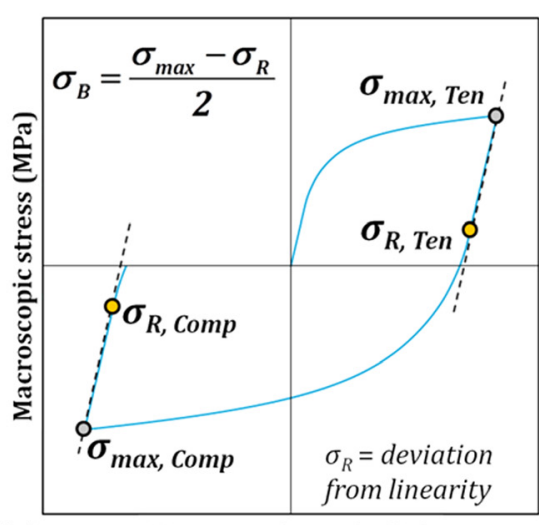

(c)

Macroscopic strain $(\%)$

FIG. 1. (a) The macroscopic stress-strain curve during cyclic loading, (b) the maximum and back tensile and compressive stresses, and (c) schematic illustration of the parameters used to estimate the back stress $\left(\sigma_{B}\right)$ in (b). The first observation of $\alpha^{\prime}$ is marked in (a).

$$
\begin{aligned}
\rho_{\alpha^{\prime}}= & 7875.96-0.297 T-5.62 \times 10^{-5} T^{2}-7.24 X_{\alpha^{\prime}}^{M n} \\
& -36.86 X_{\alpha^{\prime}}^{S i}+\left(-0.22-0.47 \times 10^{-3} T-1.855 \times 10^{-7} T^{2}\right. \\
& \left.+0.104608 X_{\alpha^{\prime}}^{N i}\right) X_{\alpha^{\prime}}^{N i}+(-206.35+0.00778 T \\
& \left.+1.472 \times 10^{-6} T^{2}\right) X_{\alpha^{\prime}}^{C}
\end{aligned}
$$

where $X_{x}^{i}$ is the solute content of element $i$ (in wt. \%) in phase $x$ and $T$ is the temperature $\left({ }^{\circ} \mathrm{C}\right)$. For the present room temperature diffusionless martensitic transformation, $X_{\gamma}^{i}$ $=X_{\alpha^{\prime}}^{i}$ and $T=25^{\circ}$ C. Since Eqs. (1) and (2) do not account for our $3 \mathrm{Al}$ wt. $\%$, we implicitly assume its negligible effect on the density ratio.

The macroscopic stress-strain during cyclic loading and the maximum stress $\left(\sigma_{\max }\right)$ at the end of each half-cycle are shown in Figs. 1(a) and 1(b), respectively. Two features are evident: (i) a pronounced Bauschinger effect manifested by early yielding upon load reversal, and (ii) tensioncompression asymmetry such that the maximum stresses during compression half-cycles are $\sim 20 \%$ higher than tension half-cycles.

Deformation twinning (the TWIP effect) and martensitic transformation (the TRIP effect) are typically accompanied by a prominent Bauschinger effect due to the generation of significant back stresses in the parent austenite matrix as dislocations pile-up at twin boundaries and the hard $\alpha^{\prime}$ phase.
During our previous investigation of a TWIP steel, a similar in-situ ND cyclic experiment along with selfconsistent modeling showed that twinning alone cannot be responsible for the pronounced Bauschinger effect. ${ }^{8}$ The magnitude of the intergranular stresses (arising in different grain orientations) was also insufficient to account for the high back stresses. Consequently, it was postulated that other intragranular sources of back stress (such as dislocation pile-ups at stacking faults) were present in the matrix. In the current TRIP-TWIP steel, interphase stresses (following $\varepsilon$ and $\alpha^{\prime}$ formation) also contribute to the Bauschinger effect. However, the quantitative estimation of the various sources of back stress (requiring TEM analyses) is beyond the scope of this study.

To this end, the Bauschinger effect was estimated via the Cottrell scheme; ${ }^{9}$ wherein the cyclic flow stress is divided into a friction stress $\left(\sigma_{F}\right)$ and a back stress $\left(\sigma_{B}\right) . \sigma_{F}$ is independent of the loading direction and is associated with shortrange interactions such as lattice friction and forest hardening effects. Classically, $\sigma_{B}$ comprises intragranular and intergranular stress contributions (here including interphase stress) and aids yielding upon load reversal. Defining $\sigma_{\max }=\sigma_{F}+\sigma_{B}$ and $\sigma_{R}=\sigma_{F}-\sigma_{B}$ leads to $\sigma_{B}=\left(\sigma_{\max }-\sigma_{R}\right) / 2$; where $\sigma_{R}$ is the yield stress upon load reversal and taken as the point of deviation from elasticity (Fig. 1(c)). For example, after the first
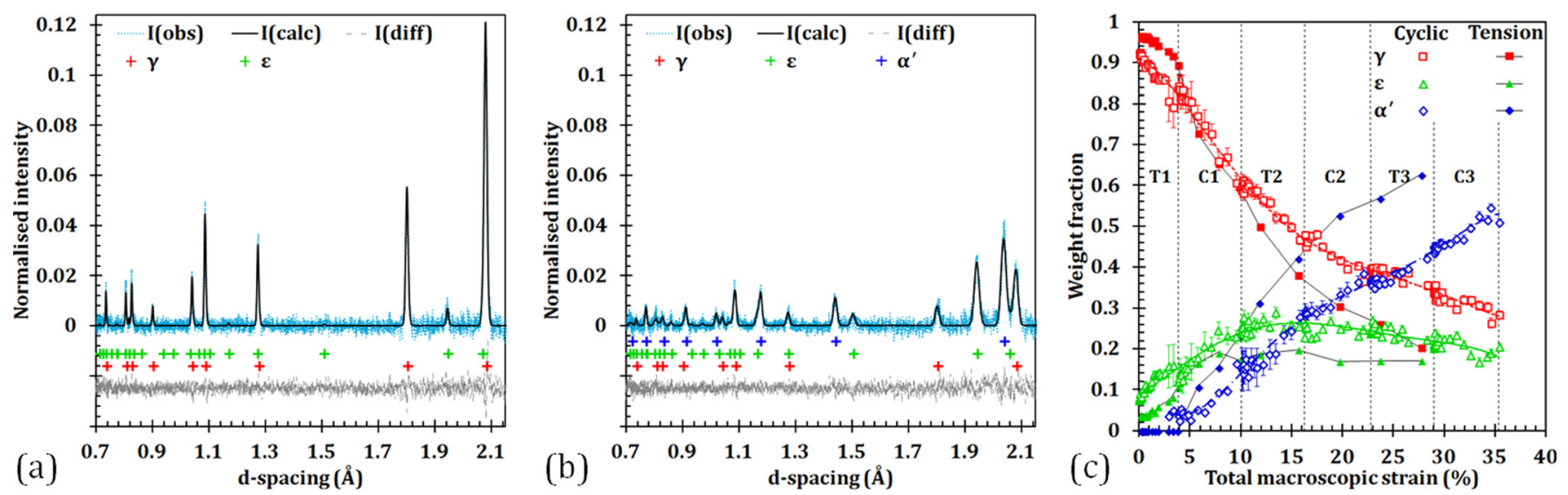

FIG. 2. Representative axial diffraction patterns (a) before the start of cycling and (b) after the third compression half-cycle. The difference curves (I(diff)) between the measured data (I(obs)) and the Rietveld refinement (I(calc)) are shown in gray. The red, green, and blue cross marks indicate the positions of the $\gamma, \varepsilon$, and $\alpha^{\prime}$ peaks, respectively. (c) Phase fractions versus the total macroscopic strain during cyclic and tensile loading. 

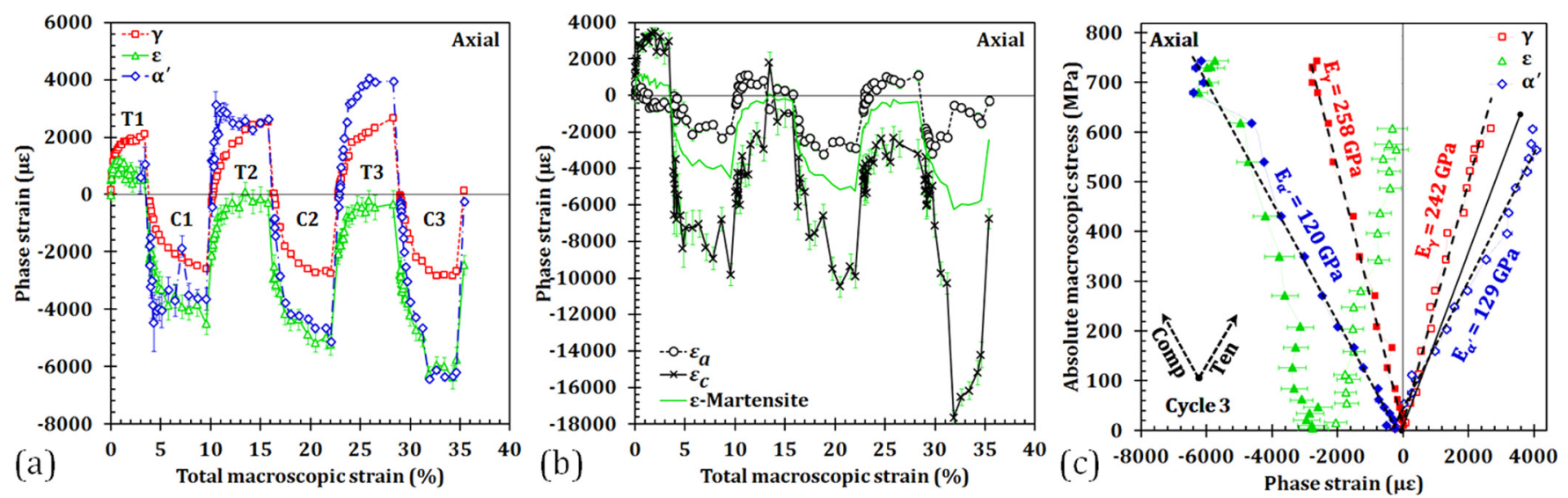

FIG. 3. Axial lattice strains versus the total macroscopic strain for the (a) phases and (b) the $a$ and $c$ lattice parameters of $\varepsilon$. (c) Axial lattice strains versus the absolute macroscopic stress during the third loading cycle. Error bars represent the statistical uncertainty in the fitting of the lattice parameters and are not visible when they are smaller than the symbols. In (c), the solid black line is the initial elastic response of $\gamma$ during the first tension half-cycle, and the lattice strains in $\varepsilon$ are offset from zero due to its overall compressive strain state.

tension half-cycle $\sigma_{\max }=400 \mathrm{MPa}$ and $\sigma_{R}=310 \mathrm{MPa}$ resulting in $\sigma_{B}=355 \mathrm{MPa} \approx 0.88 \sigma_{\max }$ (Fig. $1(\mathrm{~b})$ ). For comparison, a TWIP steel sample subjected to one cycle between strain limits of $\sim+3.5 \%$ to $-3 \%$ returned $\sigma_{\max }=390 \mathrm{MPa}$, $\sigma_{R}=265 \mathrm{MPa}$, and $\sigma_{B}=328 \mathrm{MPa} \approx 0.84 \sigma_{\max }$. The similarity in the $\sigma_{B} / \sigma_{\max }$ ratios in both TRIP-TWIP and TWIP steels and the high back stress after the first tension half-cycle (i.e., before the formation of a substantial fraction of twins and/or the hard $\alpha^{\prime}$ phase) in the present TRIP-TWIP steel indicates a significant contribution of intragranular back stresses to the pronounced Bauschinger effect. As detailed in Ref. 8, stacking faults and their intersections that are readily formed in low SFE materials act as effective barriers to dislocation motion and provide a major source of intragranular back stresses.

The observed tension-compression asymmetry (Fig. 1(b)) is characteristic of materials that deform by twinning and/or martensitic transformation. ${ }^{10}$ In the case of twinning, the asymmetry is ascribed to the directionality of twinning; wherein not all $\{111\}\langle 112\rangle$ twinning systems activated during tension are activated during compression; leading to different Schmid factors $(m)$ depending on the loading direction. Accordingly, this leads to an inherently lower yield stress in tension compared to compression. ${ }^{11}$ A similar rationale can explain martensitic transformation. Studies on single and poly -crystal metastable austenitic steels have correlated the propensity for $\varepsilon$ and $\alpha^{\prime}$ transformation with the Schmid factor of the $\{111\}\langle 112\rangle$ shear systems; such that the dependence of martensitic transformation on grain orientation was similar to twinning. ${ }^{12-15}$ Consequently, we used a generalized Schmid's law and the initial $\gamma$ texture (measured via $x$-ray diffraction) to calculate a texture-weighted average Schmid factor for the $\{111\}\langle 112\rangle$ shear systems. ${ }^{16}$ Imposing uniaxial tension returned $m=0.42$ whereas uniaxial compression returned a lower value of $m=0.36$. This indicates that both twinning and martensitic transformation are easier to activate in tension and corroborates the observed tensioncompression asymmetry.

Our Schmid factor calculations also suggest a higher rate of martensitic transformation during tension compared to compression. To verify this, the evolution of the phase weight fraction during in-situ monotonic tensile loading is included in Fig. 2(c) for comparison with the present cyclic case. While both loading cases return qualitatively similar trends, it is clear that cyclic loading records an overall slower rate of martensitic transformation due to the compression half-cycles. Here, the evolutionary trends of the $\varepsilon$ (initial increase followed by a gradual decrease) and $\alpha^{\prime}$ (monotonic increase) phase fractions imply that $\varepsilon \rightarrow \alpha^{\prime}$ proceeds at a faster rate than $\gamma \rightarrow \varepsilon$.

Fig. 3(a) shows the lattice strain evolution of the three phases in the axial direction as a function of the total macroscopic strain. Given that: (i) Rietveld refinement effectively averages out intergranular effects between different orientations within an individual phase, and (ii) the diffraction technique only detects changes in the elastic lattice strain; the Rietveld-based phase strain is necessarily proportional to the sum of the macroscopic and interphase stresses. It follows that Fig. 3(a) is an approximation (as it does not account for the transverse lattice strains ${ }^{17}$ ) of the stress partitioning between the various phases. Stress partitioning is generally caused by a combination of elastic and plastic anisotropy. Since the three phases exhibit nearly equal elastic stiffness, ${ }^{18}$ stress partitioning between them is mainly ascribed to the inhomogeneous plastic deformation due to the differences in their directional strength (hardening behavior). ${ }^{19}$

In the first tension half-cycle (prior to $\alpha^{\prime}$ formation), the $\gamma$ records higher lattice strains compared to $\varepsilon$ which exhibits a gradual decrease. In subsequent cycles (following $\alpha^{\prime}$ formation), the $\alpha^{\prime}$ exhibits the highest lattice strains in the axial direction; indicating that it acts as a reinforcing phase and carries a higher load than either $\gamma$ or $\varepsilon$. While the small $\varepsilon$ weight fraction (Fig. 2(c)) results in a larger scatter and a higher uncertainty in its lattice strain compared to $\gamma$ and $\alpha^{\prime}$ (Fig. 3), its large compressive strains are likely linked to phase transformation as follows.

During the first tension half-cycle, the decrease in the $\varepsilon$ lattice strain is associated with an increase in its weight fraction (see "T1" in Fig. 2(c)). Moreover, since the $\gamma \rightarrow \varepsilon$ transformation involves compression along the $c$-axis of the hexagonal crystal, ${ }^{20}$ the decrease in the $\varepsilon$ lattice strain can be mostly attributed to the $\gamma \rightarrow \varepsilon$ transformation. 


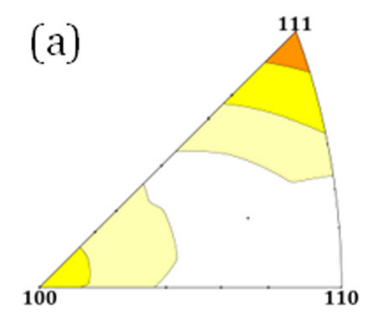

(d)

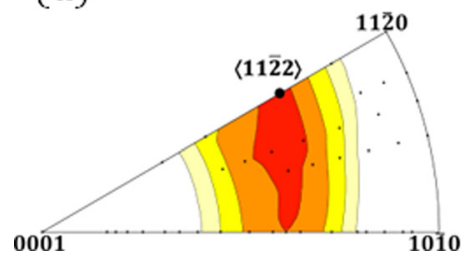

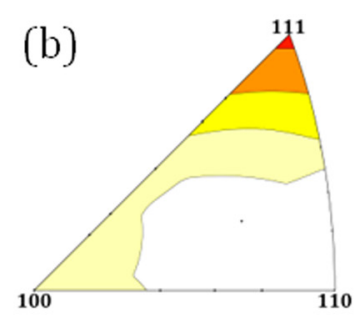

(e)

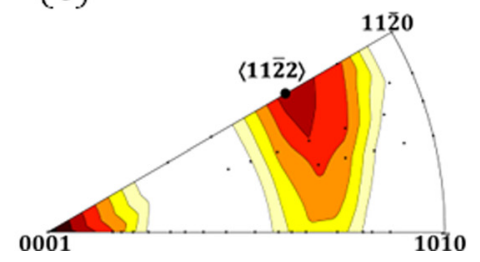

(c)

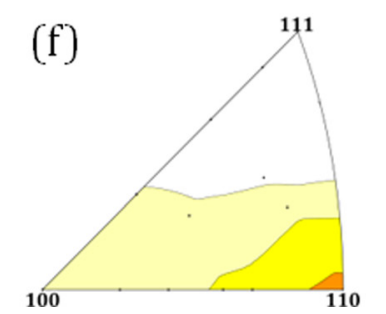

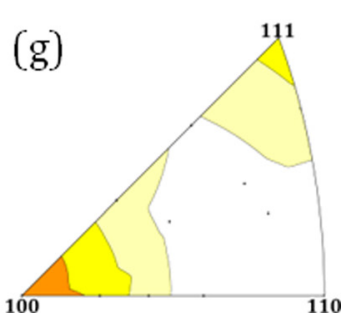

FIG. 4. Inverse pole figures in the axial direction of (a)-(c) $\gamma$, (d) and (e) $\varepsilon$, and (f) and (g) $\alpha^{\prime}$ at the (a) initial and maximum load point of the third (b), (d), (f) tension and $(\mathrm{c}),(\mathrm{e}),(\mathrm{g})$ compression half-cycles.

In subsequent cycles, $\varepsilon$ records average compressive (negative) lattice strains despite the macroscopic tensile (positive) stress. If the strains of the lattice parameters $a\left(\varepsilon_{a}\right)$ and $c\left(\varepsilon_{c}\right)$ are examined (Fig. 3(b)), $\varepsilon_{a}$ tends to follow the sign of the macroscopic stress. Alternatively, $\varepsilon_{c}$ exhibits significantly larger compressive strains such that the average $\varepsilon$ phase strain remains compressive after the first tension halfcycle and can be ascribed to the $\varepsilon \rightarrow \alpha^{\prime}$ transformation. Here, $\alpha^{\prime}$ exerts a strong uniaxial compressive stress (in the hexagonal crystal coordinate system) on $\varepsilon$ due to the larger crystal volume of the former compared to the latter. ${ }^{21,22}$

The above two paragraphs suggest that for the employed strain levels, $\varepsilon$ accommodates most of the internal strains caused by the shape misfit associated with phase transformation. ${ }^{15,19}$

To further demonstrate the interphase stresses, Fig. 3(c) charts the evolution of the phase strains as a function of the absolute macroscopic stress during the third loading cycle. Since diffraction patterns were not acquired during unloading (where macro-yielding occurred), the lattice strains only depict post-yielding behavior. Following the explanation for Fig. 3(a) and compared to the initial elastic response of $\gamma$ during the first tension half-cycle $(178 \mathrm{GPa}$, solid black line in Fig. 3(c)), the slopes of axial $\gamma$ and $\alpha^{\prime}$ during the third tension half-cycle exhibit an increase $\left(\mathrm{E}_{\gamma}=242 \mathrm{GPa}\right)$ and a decrease $\left(\mathrm{E}_{\alpha^{\prime}}=129 \mathrm{GPa}\right)$, respectively. Thereafter, during the third compression half-cycle, these slopes increase $\left(\mathrm{E}_{\gamma}=258 \mathrm{GPa}\right)$ and decrease $\left(\mathrm{E}_{\alpha^{\prime}}=120 \mathrm{GPa}\right)$ even further. This indicates that $\alpha^{\prime}$ carries an increasing portion of the macroscopic stress as its weight fraction evolves with further cycling.

Texture evolution in metastable austenitic steels is dictated by grain rotation associated with plastic deformation as well as phase transformation. The $\gamma$ IPFs (Figs. 4(a)-4(c)) do not show a discernible variation in texture at the maximum load points of the third tension and compression half-cycles. This suggests a limited grain rotation effect in $\gamma$ for the low strain levels of this study.

In Figs. 4(d) and 4(e), the formation of $\langle 11 \overline{2} 2\rangle_{\varepsilon}$ orientations is typical of the $\gamma \rightarrow \varepsilon$ transformation during both tension and compression. ${ }^{15}$ Alternatively, the formation of $\langle 0001\rangle_{\varepsilon}$ orientations during compression (Fig. 4(e)) can be linked to the large local compressive strain of the $c$-axis via basal slip. $^{23}$

In agreement with reports on the monotonic tension and compression of metastable austenitic steels, ${ }^{15}$ the $\alpha^{\prime}$ IPFs record the formation of $\langle 110\rangle_{\alpha^{\prime}}$ orientations after tension and $\langle 100\rangle_{\alpha^{\prime}}+\langle 111\rangle_{\alpha^{\prime}}$ orientations after compression. In general, cycling from: (i) tension to compression results in some $\langle 110\rangle_{\alpha^{\prime}}$ orientations (that are stable in tension) rotating towards $\langle 100\rangle_{\alpha^{\prime}}$ during subsequent compression, whereas (ii) compression to tension causes a general re-orientation of grains towards the $\langle 110\rangle_{\alpha^{\prime}}$ pole. However, considering our low strain level, the $\alpha^{\prime}$ IPFs can be directly linked to the parent $\gamma$ (even if the $\gamma \rightarrow \varepsilon \rightarrow \alpha^{\prime}$ transformation sequence occurs). ${ }^{24}$ The formation of dominant $\langle 110\rangle_{\alpha^{\prime}}$ (Fig. 4(f)) and $\langle 100\rangle_{\alpha^{\prime}}$ (Fig. 4(g)) orientations is associated with the preferential transformation of $\langle 111\rangle_{\gamma}$ and $\langle 100\rangle_{\gamma}$ orientations during tension and compression, respectively, and signifies the operation of the Kurdjumov-Sachs orientation relationship. The latter entails that during tension, $\langle 111\rangle_{\text {, }}$ orientations can transform to $\langle 100\rangle_{\alpha^{\prime}},\langle 110\rangle_{\alpha^{\prime}}$ and $\langle 221\rangle_{\alpha^{\prime}}$ orientations whereas during compression, the $\langle 100\rangle_{\gamma}$ orientations can transform to $\langle 100\rangle_{\alpha^{\prime}}$ and $\langle 110\rangle_{\alpha^{\prime}}{ }^{15}$ While the selection of the $\langle 110\rangle_{\alpha^{\prime}}$ (tension) and $\langle 100\rangle_{\alpha^{\prime}}$ (compression) orientations is probably associated with strain accommodation due to transformation, further work is needed to ascertain the exact origin of the observed orientations.

In summary, in-situ ND was used to investigate the deformation and phase transformation behavior during the cyclic loading of a TRIP-TWIP steel. A pronounced Bauschinger effect was observed upon load reversal with a significant contribution of intragranular back stresses. A higher rate of martensitic transformation was noted during tension compared to compression. The hard $\alpha^{\prime}$-martensite developed the highest phase strain whereas $\varepsilon$-martensite continued to record compressive strain as it accommodated most of the shape misfit associated with the $\gamma \rightarrow \varepsilon$ and/or $\varepsilon \rightarrow \alpha^{\prime}$ transformations.

This work was funded by the Australian Research Council-Discovery Project (No. DP130101882). Professor D. B. Santos (UFMG, Brazil) is thanked for the as-cast steel. 
The access to major research facilities program is supported by the Commonwealth of Australia under the International Science Linkages program. C.N.T. was fully supported by the U.S. DOE Project No. FWP 06SCPE401 under U.S. DOE Contract No. W-7405-ENG-36. This work has benefited from the use of LANSCE which is funded by the U.S. DOE. LANL is operated by Los Alamos National Security LLC under U.S. DOE Contract No. DE-AC5206 NA25396.

${ }^{1}$ O. Grassel, L. Kruger, G. Frommeyer, and L. W. Meyer, Int. J. Plast. 16, 1391 (2000).

${ }^{2}$ M. A. M. Bourke, D. C. Dunand, and E. Ustundag, Appl. Phys. A 74, S1707 (2002).

${ }^{3}$ A. C. Larson and R. B. VonDreele, General Structure Analysis System (GSAS), Los Alamos National Laboratory Report LAUR 86-748, 2004.

${ }^{4}$ C. N. Tupper, D. W. Brown, R. D. Field, T. A. Sisneros, and B. Clausen, Metall. Mater. Trans. A 43(2), 520 (2012).

${ }^{5}$ M. R. Daymond, M. A. M. Bourke, and R. B. Von Dreele, J. Appl. Phys. 85(2), 739 (1999).

${ }^{6}$ H. N. Han and D.-W. Suh, Acta Mater. 51(16), 4907 (2003).

${ }^{7}$ J. Miettinen, Metall. Mater. Trans. B 28(2), 281 (1997).

${ }^{8}$ A. A. Saleh, E. V. Pereloma, B. Clausen, D. W. Brown, C. N. Tomé, and A. A. Gazder, Acta Mater. 61(14), 5247 (2013).
${ }^{9}$ A. H. Cottrell, Dislocations and Plastic Flow in Crystals (Oxford University Press, London, 1953).

${ }^{10}$ D. V. Wilson, Met. Technol. 2(1), 8 (1975).

${ }^{11}$ W. F. Hosford and T. J. Allen, Met. Trans. 4, 1424 (1973).

${ }^{12}$ Y. Higo, F. Lecroisey, and T. Mori, Acta Metall. 22(3), 313 (1974).

${ }^{13}$ M. Kato and T. Mori, Acta Metall. 25(8), 951 (1977).

${ }^{14}$ T. Y. Liu, P. Yang, L. Meng, and F. Y. Lu, J. Alloys Compd. 509(33), 8337 (2011).

${ }^{15}$ P. Yang, T.-Y. Liu, F.-Y. Lu, and L. Meng, Steel Res. Int. 83(4), 368 (2012).

${ }^{16}$ A. A. Gazder, A. A. Saleh, and E. V. Pereloma, Scr. Mater. 68(6), 436 (2013).

${ }^{17}$ While not shown, the evolution of the transverse lattice strains follows Poisson's effect such that smaller compressive and tensile lattice strains develop in $\gamma$ and $\alpha^{\prime}$ during tension and compression half-cycles, respectively. Similar to the axial direction, $\varepsilon$ records compressive transverse lattice strains throughout cycling.

${ }^{18}$ K. Tao, H. Choo, H. Li, B. Clausen, J.-E. Jin, and Y.-K. Lee, Appl. Phys. Lett. 90(10), 101911 (2007)

${ }^{19}$ M. T. Hutchings, P. J. Withers, T. M. Holden, and T. Lorentzen, Introduction to Characterization of Residual Stress by Neutron Diffraction (CRC Press, 2004).

${ }^{20}$ P. Marinelli, M. Sade, and A. F. Guillermet, Scr. Mater. 46(11), 805 (2002).

${ }^{21}$ L. Bracke, L. Kestens, and J. Penning, Scr. Mater. 57(5), 385 (2007).

${ }^{22}$ K. Kwon, J. Jeong, J.-K. Choi, Y. Koo, Y. Tomota, and N. Kim, Met. Mater. Int. 18(5), 751 (2012).

${ }^{23}$ S. Merkel, H.-R. Wenk, P. Gillet, H.-k. Mao, and R. J. Hemley, Phys. Earth Planet. Inter. 145(1-4), 239 (2004).

${ }^{24}$ S. Kundu and H. K. D. H. Bhadeshia, Scr. Mater. 57(9), 869 (2007). 